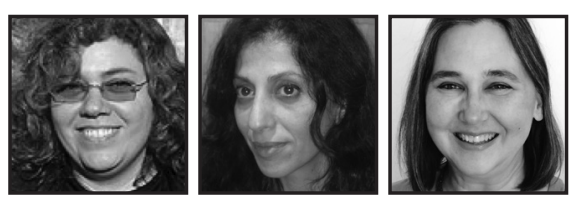

\title{
Making Room for Inquiry and Creativity From Pre-Kindergarten Through University
}

\author{
Amanda Nicole Gulla, Limor Pinhasi-Vittorio, \\ and Alison Lehner-Quam, Lehman College/CUNY
}

\section{ABSTRACT}

Professional development with teachers, whether they are in pre-K-12 schools or in higher education, creates opportunities for discussions among teachers and teacher educators about how to find spaces for creativity and the imagination within the structure of the Common Core State Standards, a set of national standards adopted on a stateby-state basis in the U.S. Two education faculty members and an education librarian from a large city university held workshops, bringing together university faculty in arts and humanities, science, mathematics and education, and pre-K-12 teachers to explore the potential for inquiry and creativity in the Common Core State Standards.

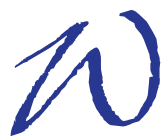
hat do education faculty, arts and sciences faculty, pre-K-12 teachers, and school librarians have to teach each other about teaching and learning? How can we help each other find ways to make richly complex texts and ideas accessible to students who may struggle with basic skills?

With these questions in mind we, three faculty members from Lehman College's School of Education and Library, collaborated on a project for professional development that we hoped might spark a dialogue that could help educators consider ways they might bring inquiry and creativity into their classrooms.

In response to a Request for Proposals from the City University of New York (CUNY's) Professional Development and Common Core State Standards Alignment Initiative for Arts and Sciences Faculty, we designed a workshop series bringing together faculty 
across disciplines and departments. Conscious of the Common Core's emphasis on "career and college readiness" in New York State (NYSED, n.d.), we wondered whether liberal arts and sciences faculty would see these standards as preparing students for college-level work. The workshop was broken into two sessions, taking place one week apart.

The project aimed to support Lehman College's Natural and Social Sciences, Arts and Humanities, and Education faculty who work with teacher candidates and undergraduate students in finding opportunities for inquiry-based learning and creativity within the context of the Common Core State Standards. In particular, the project allowed participants to explore the use of inquiry-based learning as a tool in teaching complex texts and ideas and in developing students' ability to make evidencebased arguments.

Maxine Greene (1995) advocates for the role of the imagination in education as a way of "decentering ourselves" (p. 30) to remind us that education is not simply the acquisition of fact and skills, but a means of taking one's place in the world. As students are encouraged to question their own understanding, their teachers need to have the experience of immersion in the kinds of decentering experiences that can be the outgrowth of creative engagement.

Professional development at all levels, from early childhood to higher education, can help educators find opportunities to integrate artistic expression and multimodal literacies across the curriculum. It is essential that professional development workshops that ask teachers to consider the role of creativity in their work provide a safe space for such "decentering" experiences as Greene describes. We as college professors and teacher educators, in turn, need to help college students and teacher candidates find contexts for such experiences within the curriculum as we help them negotiate the constraints and the possibilities under which they function.

\section{Some Background on the Common Core and Its Impact on Teaching and Learning}

In this paper we will provide some background knowledge about the Common Core Standards and the impact they have had on teaching and learning in U.S. schools. As the standards movement in education has begun to develop international momentum, the challenges faced by American schools might be useful to consider in other contexts. 
This system of standards and assessments can trace its roots internationally to the United Kingdom's Thatcher administration, when the nation adopted a set of standards in 1988 to evaluate core competencies in reading, writing, and mathematics (Volante \& Earl, 2013). According to the authors, policies mandating curriculum requirements and corresponding standardized tests have since been implemented in other European countries as well as North America, Australasia, and parts of Asia. Similar to the U.S., where standards have been adopted on a state-by-state basis, Canada's 10 provinces have implemented assessments by which schools are ranked and compared. The notable difference between the U.S. and Canada is that Canada mainly uses this data for the purpose of school improvement, rather than the American high-stakes tests that is used to evaluate student and teacher performance. In fact, a 2013 report by Action Canada refers to the role of standardized testing in the U.S., citing a study that found that, "70 percent of US school boards scaled back time on teaching subjects other than literacy and numeracy in order to improve test scores" (Despres, Kuhn, Ngirumpatse, \& Parent, 2013, p. 10). The report recommends that Canada not allow testing to play as central a role in education as American schools have. Volante and Earl note the difference between the American and Canadian approaches to standards thusly: "For the most part, external test results are used to facilitate school improvement and do not carry high-stakes consequences for teachers or students in Canada" (2013).

The Common Core Standards (CCSS) were developed in response to the federal No Child Left Behind law and were adopted on a state-by-state basis in the U.S. The CCSS were published in the United States in 2010 and, as of this writing, have been adopted by 44 out of 50 states plus the District of Columbia. The standards established their primary goal as career and college readiness by emphasizing close reading of complex texts and evidence-based writing-habits of mind characteristic of many college curricula (Hess, 2012). As a result of a major federal funding incentive called Race to the Top, which was awarded to states willing to adopt common standards and the accompanying assessments developed in the following years, pre-K-12 schools are under pressure to prepare students for high-stakes tests in ELA and mathematics (Bowling \& Pickerill, 2013; Porter, Fusarelli, \& Fusarelli, 2015; Ujifusa, 2013).

The intention in developing Common Core Standards (2015) was to support "criticalthinking, problem-solving, and analytical skills that are required for success in college, career, and life." The standards for reading literature in grades 6-12 demand "rigor" and "increasing complexity."1 In service of these goals, the English Language Arts (ELA) standards were developed with an emphasis on reading non-fiction texts and writing evidence-based arguments. In many of the states in the U.S. that have adopted CCSS, this emphasis on reading non-fiction texts and writing evidence-based arguments is 
reflected in high-stakes testing. Because these tests carry significant consequences for students, teachers, and schools, the enormous pressure to prepare students can leave little room for creative and imaginative work in the classroom. The consequence is a loss of creativity's essential contribution to higher level thinking that "demands connections, associations, linkages of conscious and unconscious elements, memory and emotion, past, present and future merging into the process of making meaning" (Sullivan, 2009, p. 121).

The intensive testing regime and demand from school administrations that teachers devote substantial amounts of time to preparing students for these tests means that there is little room in the school year for expressive writing or exploratory reading. In fact, the standards do not even value the experience of reading whole books. For one school administrator, explaining the Common Core's "critical shift" in school reading: "We look at teaching literature as teaching particular concepts and skills. So we maybe aren't teaching an entire novel, but we're ensuring that we're teaching the concepts that that novel would have gotten across" (Strauss, 2014).

The notion that teachers would choose for students what concepts a novel "would have gotten across," rather than allowing students to discover them unfolding through the course of reading a whole book as its author intended, seems antithetical to the CCSS's stated goal of career and college readiness, unless one's idea of college work is consistent with consuming predigested concepts, served out of context. The decision to only read excerpts, rather than whole books, seems to be an argument in favor of expediency that presumes that the teacher and the assigned, sanctioned curriculum are the sole delivery system for anything valuable that might happen in the classroom; as if reading a novel cover to cover were a frivolous waste of time as long as the "concepts" could be gotten across more efficiently. This top-down approach to teaching is the very antithesis of inquiry-based learning, in which students explore ideas through guided research, writing, and engagement in multimodal literacies.

\section{The Common Core Standards and Inquiry-Based Learning}

The language of the CCSS appears to promote teaching strategies consistent with inquiry. Kenna and Russell (2015) point to the large number of higher-order thinking verbs in the standards, which "suggest that student/learner-centered methods of instruction are favored over teacher-centered methods of instruction" (p. 29). 
However, in one widely criticized teaching strategy video on the New York State website for the CCSS, ${ }^{2}$ David Coleman, author of the ELA standards, offers a model for teaching Martin Luther King's seminal text, Letter from a Birmingham Jail, which is rooted in the traditions of New Criticism (Sulzer, 2014), in which the meaning of a text lies solely in the words on the page and not in the understandings of the reader. This approach runs counter to the essence of inquiry-based teaching and learning. In Coleman's video, he eschews techniques such as activating students' prior knowledge and pre-reading strategies that would help situate readers for deep engagement with King's ideas. His recommendation that teachers read the first paragraph aloud to find the "argument King is pushing against" deals exclusively with the claim/counterclaim structure promoted in the Common Core writing standards, ignoring the social, cultural, and historical context for King's writing. This would be an excellent strategy to prepare students for tests that involve cold readings of challenging texts, but it does not promote engagement or ongoing inquiry into deeper ideas. The approach Coleman advocates in this video has a direct link to the CCSS's insistence on close reading which restricts itself to the words of the text and does not engage the students' background knowledge as critical reading would. It is representative of "a curriculum that de-emphasizes students' worlds," thus obstructing their "making sense of the word" (Ferguson, 2015). For Ferguson, as for Freire, "such obstruction is an act of oppression."

The demand for curriculum driven by high-stakes testing presents an obstacle for the kind of thoughtful engagement that characterizes inquiry-based learning (Cartwright \& Noone, 2006). Educators, like Maxine Greene, concerned with critical literacy and social justice, have issued a call for educators to awaken their imagination and to teach between the cracks; creating spaces for nontraditional teaching and thinking, where students are allowed "to ask why" and "to think differently" (p. 2) and to feel comfortable with uncertainties. Authentic learning experiences require the learner to negotiate the meaning of new ideas and a broad range of texts in multiple forms through an ongoing process of inquiry (Pinhasi-Vittorio \& Vernola, 2013). This form of inquiry encourages cognitive leaps; permitting learners to "imagine things as if they could be otherwise" (Greene, 2010). For Greene (1995), imagination is essential in education. She states: "of all our cognitive powers, imagination is the one that permits us to give credence to alternative realities. It allows us to break with the taken-for-granted, to set aside the familiar distinctions and definitions" (p. 3). Imagination and creativity are essential skill sets that might allow educators to support a broad range of learning needs and styles. "It provides a means of constructing a pedagogy which does not leave students demoralized, but rather provides them with a hopeful way" (Cartwright \& Noone, 2006, p. 3) and leaves room for questions that ask: "what if," "why," and "how." Imaginative thinking and creativity are possible under the constraints of CCSS if we focus on the 
aspects of the standards that encourage active engagement by students. It is frequently the case, however, that teachers report feeling unsupported in such endeavors by their administrators (Gulla, 2007). At such times, it is especially important to support teachers in their efforts to find room for inquiry within the constraints of the CCSS.

Our purpose in offering this professional development workshop series has been to find those meeting points between the standards that define the skills deemed necessary for career and college readiness and the agency fostered by student-driven inquiry.

Therefore while the CCSS limits approaches to complex reading material to the "four corners of the text" (Coleman \& Pimentel, 2012), there is potentially room for a broad range of approaches to allow for individual readings that may enrich a student's experience of a text in unpredictable ways that are unlikely to count on any test.

In an inquiry-based teaching and learning environment, the teacher models and facilitates the inquiry process. Inquiry demands that learners explore concepts embedded within the content being studied through open-ended questions. Teachers need to create the conditions that support developing scholarship through higher-order questions that ultimately lead to students forming their own questions (Wolf, 1987). This type of inquiry is a process that involves ongoing reciprocal interactions with content, with the classroom environment (Bakhtin, 1981), with peers (Vygotsky, 1978), and with teachers.

Although we are not advocating for the implementation of the CCSS, we are aware that it is the reality of public schools in New York State and, as such, we are compelled to find ways to find room for creativity and imagination while pushing the boundaries of thinking toward socially just practices. We made a conscious decision to center the workshop on interrogating the CCSS alongside an inquiry-based approach to learning. Our research questions focused on classroom practice and practitioners:

- What lessons might we be able to learn from pre-K-12 educators as they interpret and enact the CCSS?

- What role(s) can inquiry-based learning and creativity play in helping to prepare students for higher education and careers?

The professional development project provided a platform for faculty across disciplines to work on creative exploration of the use of inquiry-based learning as a tool in teaching complex texts and the development of evidence-based arguments 
as called for in the CCSS English Language Arts (ELA) standards. ${ }^{3}$ Our purpose was to provide an opportunity for faculty members who would rarely have a chance to collaborate, to learn from each other. The intention was to create a dialogue amongst teacher educators and arts and sciences faculty about how they might use creative and imaginative approaches to enrich students' understanding of complex texts and ideas. This would also expose participants to a range of perspectives while reexamining the conventional approaches to reading, writing, and thinking within the traditions of their respective disciplines. Moreover, we encouraged faculty to share the various ways in which they seek to support students in engaging with challenging ideas and complex texts.

\section{Inquiry Into Inquiry: The Workshop}

Our two-part workshop consisted of an exploration of the nature of inquiry and text complexity. We also included a panel discussion of pre-K-12 educators sharing the ways that they incorporate creativity and inquiry into their teaching within the context of mandated standards and curricula.

Participants in our workshop included professors from the campus Library as well as from English, Psychology, Sociology, Chemistry, and Education departments. To situate the discussion, we asked participants to offer a visual representation of the practice of inquiry within their respective fields using physical gestures, poses, and expressions. These embodied representations moved our colleagues into the realm of nonverbal communication - a realm that is seldom explored among academic faculty, thereby providing an opportunity for the kind of "decentering" experience we sought. This activity led us into a lively discussion of the nature of inquiry and what it requires of them.

The group was divided into halves so that each half would have an opportunity to observe the other as they performed their gesture or movement representing "inquiry." The observers were invited to look closely and identify what they noticed each person doing. We structured the activity to limit response strictly to observations and descriptions, forcing them to hold off on interpretations and analysis.

The range of movements, gestures, and facial expressions was wide. One participant noticed that a colleague made shaping or molding gestures, which were later interpreted as an effort to integrate, to make ideas cohere. Another observed someone 
who was trying to fit pieces together to grasp the whole. Some gestures appeared playful while others seemed to express a struggle. Some turned their heads or hands inward in a gesture that suggested they were seeking isolation. For one, inquiry was social and the gesture seemed to encourage others to ask more questions.

The intention behind this activity was to thoroughly involve the participants in the exploration of inquiry through the use of bodily/kinesthetic knowledge. As academics we are so used to being disembodied thinkers, talkers, and writers that we seldom afford ourselves the benefit of exploring an idea through the lens of physical movement, using body and gesture to create metaphors for our experiences. Through involvement of the body, we open the door to imaginative learning that goes beyond the text-based approach of the CCSS and indeed most academic work. Allowing the time to be in the role of the participants and, thereafter, observer, stimulated their curiosity and positioned them in a teacher-researcher mode rooted in an ethnographic approach. Looking at the physical manifestations of individual inquiry stances provided rich language to launch the discussion, making the interpretation and analysis more meaningful than it would have been otherwise.

The focus of the discussion shifted to the topic of inquiry within the various academic disciplines represented in the room. A chemistry professor opened the discussion by diagramming the scientific inquiry process on the white board: starting with a claim (hypothesis), testing the claim (deduction), criticism, and then analysis. A literacy professor came up to the white board and replaced deduction with induction, which is typical of inquiry in his field. An artist in our group started inquiry with observation. Inquiry involved stepping back and letting go of preconceived ideas and biases, looking at things from different angles. An English professor remarked that the shape of inquiry may be rambling and tentative, rather than linear or neat. It may spiral and have an iterative quality as it moves from the unclear to clarity. This process could take place when studying any kind of object or being. One teacher educator talked about inquiry into student learning and the need to model questioning as a practice.

Inquiry may also be a way of being in the world, and in the classroom, one that involves observation, curiosity, questioning, and wonder. A counselor educator commented that inquiry is the desire to know, humbly noting that there is a need to know more. For a psychology professor, inquiry is ongoing and active. A science educator stated that inquiry is not neat or complete, and the chemistry professor agreed that there are always more questions at the end of the cycle. 
This exploration of inquiry as a practice, and as a stance, set us up for the next phase of the workshop-inquiry into a complex text. Our idea was to examine the professors' own notions about what constitutes a complex text in various contexts and consider what strategies they use to support their students in understanding complex texts in their courses. The CCSS have a great deal to say about text complexity. ${ }^{4}$ We looked at our colleagues' practices alongside approaches to text complexity as they are described within the CCSS.

\section{Text Complexity and Argument}

One of the questions that arose for us as we designed the workshop was whether there would be agreement about the characteristics that identified a text as complex. We also wondered about the range of strategies faculty members in various disciplines used to address the challenges their college students might face in reading complex texts. A search of the New York State CCSS website reveals this sentence regarding the importance of text complexity: "As a result of CCSS-aligned instructions, Students will readily undertake the close, attentive reading that is at the heart of understanding and enjoying complex works of literature" (NYSED, 2012b). The authors of the CCSS recommend a mix of quantitative and qualitative measures including the Lexile level to determine the degree of a given text's complexity. Early in the workshop we asked participants to describe the characteristics of a complex text. We began by asking a four-part question:

What is a complex text?

What makes a text complex for you?

What makes a text complex for your students?

What makes a text complex in your field?

Here were some of their responses:

- Texts with multiple layers of meaning may not unfold all at once (e.g., music-not a pop song, you need to hear it many times to get it).

- There is a density of material. The big picture of why you need to know all these details often gets lost. The text contains jargon.

- Complex texts may be layered and highly abstract, often dense. Requires prerequisite text, prior knowledge. 
- The text may seem abstract. The reader's background knowledge is not there.

- Theoretical perspective may not be apparent or may be latent.

- Can we separate the complex text from the knowledge presented?

- A text may be complex without being dense or wordy if the ideas it contains are complex.

The participants' comments about complex texts-that they are layered, may be non-linear, and require some background to understand-suggest an approach to reading these texts that values multiple layers of questioning, ample time for engagement, and bringing prior knowledge to bear-an approach that is markedly different from the one Coleman suggests. In short, we had set the stage to explore a model of inquiry in support of reading complex texts.

In preparation for the workshop, we had asked participants to come prepared with a specific challenging text from a course they taught. In their small groups, they shared these texts and talked about strategies they use in their classes to support students when they had difficulty comprehending the readings.

At the end of the first day of the workshop, each group chose one of the approaches to aiding student comprehension, and worked together to construct an argument with a clear claim in support of the instructional approach. Following the guidelines of the 8th Grade Common Core State Standard ELA Curriculum regarding the construction of an argument, the participants also needed to include a counterclaim to their argument (NYSED, 2012a). It appeared that the participants were deeply invested in the activities. There was laughter and lively discussion as they worked diligently in their groups. As each group presented its arguments and counterclaims, we were struck that all of these professors from a wide range of disciplines took responsibility for supporting their students as readers. Rather than insist that the responsibility of understanding the reading material lay solely with the students, each faculty member had thoughtfully considered strategies to scaffold the reading.

Following the group presentations of their arguments in support of strategies for teaching complex texts, we asked them to present their arguments in a different form than they had previously; we wanted to engage the participants in imaginative thought to open up different venues of conceptualizing ideas. The stress was on thinking of a non-conventional way to present their argument. We hoped that experiencing the 
embodiment exercises during the workshop might have primed them to think outside of the scholarly box and consider alternative ways of viewing an argument and complex text. We stressed that it was not important which form they used as long as they were able to share their claims in a different mode than their original presentation. The participants worked with their groups during the week between the first and second sessions, getting ready to present their claims and counterclaims.

The subsequent week, the four groups presented their arguments. Although three of the four groups wrote original poetry as the vehicle for presenting their argument, each group used its poems in unique ways.

The first group distributed paper frames of varying sizes and asked us to look around the room and to comment on how the frame focused our observations. The use of the frame was a visual metaphor for the group's claim that students need the teacher's help in focusing on the key ideas within a text. One of the professors then read an original humorous poem called Night Falls on the Forest of Imaginings, which expressed the panic of "ivory tower newbies" when they "trek into the forest of imaginings" and experience grotesque consequences when confronted with a text whose complexity exceeds their capacity. The poet in this group used a series of ever-more alarming metaphors to suggest the feeling of being lost in a forest of words:

\section{The tendrils of creeping vines grow, not slowly,} winding about our limbs and necks as if caught between a decidedly Kantian synthetic statement and a Marxian dialectic contradiction in itself. Three more classmates gone, devoured by the void. We run! No-we hobble deeper into the forest.

The dramatic imagery cast a comical light on the students' anxiety, ending with this plea, evoking the familiar image of the beleaguered student lost in the forest of academic jargon:

We're freshman art majors!

We didn't want this! Can't we just ask Google?

The second set of presenters argued for the value of looking at complex texts in small groups. Unlike the first group, which used the forest as an intricate metaphor for students' reading complex texts, the second group composed a simpler, more straightforward poem about useful approaches to studying complex texts. The main 
presenter of that group prefaced her reading with an apology for her skills as a poet. Another participant said that it felt awkward and strange to think outside the box. Moments like this encourage empathy for our students who are often in this position.

The third group presented a poem that argued for the importance of providing a purpose for reading prior to handing out a text. One of the presenters commented that the process of writing the poem helped to clarify the claim for which they were arguing.

The fourth group used a music video by the legendary Nigerian Afro beat musician Fela Kuti to serve as its complex text. It provided readings and a video to illustrate the value of historical context in understanding a complex text, to illuminate the complexity of the music. The group pointed out that understanding the political content of Fela's music requires listening multiple times and the support of contextual information.

In all presentations, participants expressed that by using creative approaches to present an argument they were pushed to explore a claim, rather than asserting and supporting it-facilitating the line of questioning. Rather than proving their claims, there was an acknowledgement that inquiry often raises more questions than answers. It further pushed them to think of their argument in a different way, as they reexamined it and present it in an unorthodox manner. This process sets the stage for socially just practices and furthers inquiry as it opens participants up to dialogue with alternative perspectives. Once the higher education faculty had been steeped in a discussion of the CCSS, we felt it was important for them to hear the perspective of pre-K-12 educators.

\section{The Panel Discussion}

The panel consisted of three educators with a broad range of experiences in schools. Diana Behan is a recently retired birth-12 teacher, reading specialist, literacy coach, and adjunct instructor in the Literacy Studies Graduate Program; Michael Dodes is a high school Library Information Specialist; and Molly Sherman is a high school English and ESL teacher in an international high school with a student population of recent immigrants from all over the world. The three panelists were each asked to talk about the realities of finding room for inquiry and creativity within the CCSS (Behan, Dodes, \& Sherman, 2014).

Each of the panelists shared strategies they had used to deepen their students' understanding of complex texts. These included writing poems in response to 
non-fiction articles, staging debates about the motivations of characters in stories, and teaching research and inquiry methods. As a result of these techniques, students' writing and their thinking improved, and their test results confirmed that real understanding of a text often goes beyond its four corners. One panelist described the challenges of sometimes having to create room for creative and imaginative work within the limitations of scripted curricula.

Workshop participants were eager to ask questions of the pre-K-12 panelists about the reality in schools as well as what higher education faculty can expect from Common Core educated students. The faculty wondered if it could expect different skills from college students in the future. The Library, Arts and Humanities, and Science professors, as well as teacher educators, were eager to learn from the panelists what they might do to empower new teachers to integrate inquiry and creativity in their teaching within the framework of the CCSS.

We started the workshop with activities that "decentered" the participants and drew upon their creativity and imagination. Discussions pushed the boundaries and raised possibilities for inquiry and creativity within the constraints of the Common Core. Participants enjoyed the activities and experimented with new terms and new ways of thinking, viewing, and teaching. When the three guest speakers presented their own daily realities of finding room for creativity within the Common Core, our colleagues were hit full force with the challenges of working within these often oppressive confines. Upon reflection, we realized that if we had placed the guest speakers at the beginning of the workshop, the participants would have had time to consider the constraints described by the pre-K-12 panelists and to explore the creative ways of teaching between the cracks.

\section{Discussion (Findings)}

Looking back at the professional development and examining the data, we came across three threads that were supported by the evidence; 1 ) The language of the CCSS appears to promote inquiry, but the reality of the implementation does not support that approach; 2) Some teachers do find room for inquiry and creativity, but it is very challenging; and 3) Creative thinking and embodiment can help learners gain more insight into an idea or an argument. 
1. The language of the CCSS appears to promote inquiry, but the reality of the implementation does not support that approach.

When the panel of seasoned teachers and a librarian presented its work (Behan et al., 2014), Sherman talked about the teachers' fear of losing their jobs unless they followed the standards and so they didn't take risks with their teaching. Behan supported Sherman's point, centering on the younger age of her students, when she used a scripted curriculum that provided readings that were too complex for the reading level of young children. In response, Dodes talked about wanting to develop readers - trying to ensure that books that he recommended were at an appropriate level of complexity to meet the needs of each student.

Continuing the discussion of text material, Sherman asserted the need to find multiple articles on the topic of immigration for her students because the published packets of articles provided by the school were not engaging and contextually rich enough for her students. In each case, the teachers and librarians sought out resources that would be of high interest to their students and might ignite their passion for learning. These materials were selected to support each student's individual inquiry.

\section{Some teachers do find room for inquiry and creativity, but it is very challenging.}

The participants in the workshop agreed that seasoned teachers with tenure are in a better position in taking risks and "subversively" including inquiry and creativity. Yet, in order to do so, teachers need to know the Common Core very well so that they can defend their teaching practices with the school administration. The growing concern is about new teachers who are lost and feel pressured to follow the standards to the fullest. This pressure comes top down from state officials, administrators, district supervisors, principals, teachers, and eventually is felt by the students. When teachers feel supported in school, and know that there is room and tolerance for different types of teaching and learning, they can then be available to engage their students in authentic learning.

\section{Creative thinking and embodiment can help learners gain more insight into an idea or an argument.}

Several of the workshop participants commented that finding different modalities for expressing their ideas deepened their understanding and made the experience memorable. 
If we can recognize that all of us have different ways of defining research, inquiry, learning, text complexity, as well as different modalities in expressing these concepts, we will be open to different instructional styles to address the needs of a broad range of learners.

The creative process is integral to inquiry-based learning. Unlike Coleman's stance that understanding of the text can be gained by "following the details," we contend, like Louise Rosenblatt (1978), that the "poem exists in a transaction between the reader and the text" (p. 100). Such transactions demand that readers bring their own histories and understandings into their readings in order to make the text come alive. De-centering approaches, such as the ones modeled in this workshop series, invite multiple perspectives that can deepen understanding of texts. Furthermore, an embodied understanding gained through writing and/or art making allows the learner to reason through the problem in a way that does not occur in the process of "close reading" as Coleman performs it. For Coleman, the meaning resides completely within the text and not within the reader. Our intention in having participants incorporate creativity into the presentation of their arguments in support of strategies for teaching complex texts was to have them consider the argument from a different angle, "to disclose the ordinarily unseen, unheard, and unexpected" (Greene, 1995, p. 28).

Professional development workshops, if structured in a way that encourages open dialogue and questioning, provide opportunities for educators to share resources and to support each other. Following the workshop, several faculty members discussed ways in which they might incorporate some of the strategies they had learned into their courses. An art education professor told us that she was inspired to try the contextual activity that she observed around Fela Kuti to enhance the reading of Maxine Greene's work in her methods class. The chemistry professor mentioned that he wanted to introduce more writing into his class, which was inspired by a conversation with another workshop participant. One participant expressed a desire to offer different ways of presenting the same lesson depending upon the needs of the students, and another planned to use more collaborative and mixed-media work in class.

It is our hope that this workshop series has sparked an interdisciplinary conversation about finding the possibilities for inquiry and creativity in teaching that will continue to inform all of our work with students from pre-K through graduate school. 


\section{Notes}

1. Please see http://www.corestandards.org/ELA-Literacy/RL/introduction-for-6-12/

2. Please see www.engageny.org

3. Please see http://www.corestandards.org/ELA-Literacy/

4. Please see http://www.corestandards.org/ELA-Literacy/standard-10-range-qualitycomplexity/measuring-text-complexity-three-factors/

\section{References}

Bakhtin, M. M. (1981). The dialogic imagination: Four essays. Austin, TX: University of Texas Press.

Behan, D., Dodes, M., \& Sherman, M. (2014). Panel discussion. In A. Gulla, A. Lehner-Quam, \& L. Pinhasi-Vittorio, Inquiry and creativity in higher education: Fostering dialogue between teacher educators and arts and sciences faculty. Bronx, NY.

Bowling, C. J., \& Pickerill, M. (2013). Fragmented federalism: The state of American federalism 2012-13. Publius: The Journal of Federalism, 43, 315-346.

Cartwright, P., \& Noone, L. (2006). Critical imagination: A pedagogy for engaging pre-service teachers in the university classroom. College Quarterly, 9(4).

Coleman, D., \& Pimentel, S. (2012, April 12). Revised publishers' criteria for the Common Core State Standards in English language arts and literacy, grades 3-12. Retrieved from http://www.corestandards.org/assets/ Publishers_Criteria_for_3-12.pdf

Common Core State Standards Initiative. (2015). English language arts standards. Retrieved from http://www.corestandards.org/ELALiteracy/RL/introduction-for-6-12/
Despres, S., Kuhn, S., Ngirumpatse, P., \& Parent, M. (2013). Action Canada Task Force Report: Real accountability or illusion of success?: A call to review standardized testing in Ontario. Retrieved from http://testingilIusion.ca/wp-content/uploads/2013/01/ illusion_of_success_EN.pdf

Ferguson, D. (2015). Martin Luther King Jr. and the Common Core: A critical reading of close reading. Rethinking Schools. Retrieved from http://www.rethinkingschools.org/ archive/28_02/28_02_ferguson.shtml

Greene, M. (1995). Releasing the imagination: Essays on education, the arts, and social change. San Francisco: Jossey-Bass.

Greene, M. (2010). Prologue to art, social imagination and action. Journal of Educational Controversy, 5(1).

Gulla, A. (2007). Thirteen ways of looking at a blackboard: Nurturing creativity and developing voice in preparing English teachers. The New Educator, 3, 335-350.

Hess, F. (2012, June 4). Straight up conversation: The Common Core architect and new College Board president David Coleman. Education Next. Retrieved from http://educationnext.org/straight-up-conversationcommon-core-architect-and-new-collegeboard-president-david-coleman/ 
Kenna, J. L., \& Russell, W. B. (2015). Secondary social studies teachers' time commitment when addressing the Common Core State Standards. Journal of Social Studies Education Research, 6(1), 26-48.

NYSED. (2012a, October 26). New York State P-12 Common Core learning standards for English language arts and literacy. Retrieved from https://www.engageny.org/resource/newyork-state-p-12-common-core-learningstandards-for-english-language-arts-andliteracy

NYSED. (2012b, December 5). Middle school ELA curriculum video: Close reading of a text: $M L K$ "Letter from a Birmingham jail". Retrieved from https://www.engageny.org/resource/ middle-school-ela-curriculum-video-closereading-of-a-text-mlk-letter-from-birmingham-jail

NYSED. (n.d.). EngageNY. Retrieved from https:// www.engageny.org

Pinhasi-Vittorio, L., \& Vernola, S. (Spring, 2013). The arts to encourage multiple perspectives and promote social justice. Journal of Language and Literacy Education, 9(1), 54-72. Retrieved from http://jolle.coe.uga.edu/ wp-content/uploads/2013/05/The-Arts-toEncourage-Multiple-Perspectives.pdf.

Porter, R. E., Fusarelli, L. D., \& Fusarelli, B. C. (2015). Implementing the Common Core: How educators interpret curriculum reform. Educational Policy, 29(1), 111-139.

Rosenblatt, L. (1978). The reader, the text, the poem: The transactional theory of the literary work. Carbondale, IL: Southern Illinois University Press.
Strauss, V. (2014, August 27). The quote that reveals how at least one corporate school reformer really views students. Washington Post. Retrieved from http://www.washing tonpost.com/blogs/answer-sheet/wp/ 2014/08/27/the-quote-that-reveals-how-atleast-one-corporate-school-reformer-reallyviews-students/

Sullivan, A.M. (2009). On poetic occasion in inquiry in Poetic Inquiry: Vibrant Voices in the Social Sciences. Prendergast, M., Leggo, C., Sameshima, P. (Eds.) Rotterdam, The Netherlands. Sense Publishers.

Sulzer, M. (2014). The common core standards and the "basalization" of youth. English Teaching: Practice and Critique, 13(1).

Ujifusa, A. (2013, February 4). Pressure mounts in some states against common core. Education Week. Retrieved from http://www. edweek.org/ew/articles/2013/02/06/20com moncore_ep.h32.html

Volante, L., \& Earl, L. (2013). Standards, accountability and student assessment systems: An overview. Education Canada. Retrieved from http://www.cea-ace.ca/education-canada/ article/standards-accountability-and-student-assessment-systems

Vygotsky, L. S. (1978). Mind in society: The development of higher psychological processes. Cambridge, MA: Harvard University Press.

Wolf, D. P. (1987). The art of questioning. Academic Connections, Winter, 1-7. 


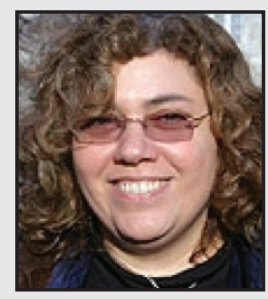

Amanda Nicole Gulla is an Associate Professor of English Education at Lehman College of the City University of New York and the Professional Development Liaison for middle and high schools. She is on the Board of Directors of the Maxine Greene Center for Aesthetic Education and the Social Imagination, and co-edits their newsletter. Her research and publications include the topics of aesthetic education, poetic inquiry, and the formation of teacher identity. She is also a poet whose work has appeared in several literary and scholarly journals. She is the author of a poetry chapbook, A Banner Year for Apples, Post Traumatic Press, 2010.

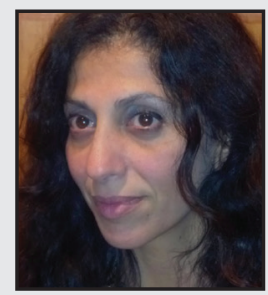

Limor Pinhasi-Vittorio is an Associate Professor of Literacy and the Coordinator of the Graduate Program in Literacy Studies. Her research focuses on examining the role of literacy and its development in the lives of various marginalized groups. Some of her recent publications examine the interplay of traditional and nontraditional forms of literacy in advancing the academic success of failing youth in the inner-city schools. Her practice is centered on the development of writing, aesthetic education, and the use of imagination as ways to promote critical literacy and social justice.

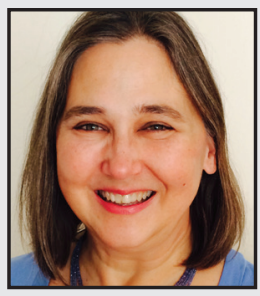

Alison Lehner-Quam, Education Librarian at Lehman College, supports School of Education faculty and students by teaching information literacy classes, collecting education materials, creating online resources, and providing reference services. She is a member of the New York City Department of Education/City University of New York Library Collaborative as well as the New York City Schools Library Services Council, where she chairs the advocacy committee. She has developed a library reading series for the Lehman Child Care Center. Prior to her appointment at Lehman College, she developed and directed the Lincoln Center Institute library. 